\title{
Revealing the painterly technique beneath the surface of Vermeer's Girl with a Pearl Earring using macro- and microscale imaging
}

\author{
Abbie Vandivere $^{1^{*}(\mathbb{D}}$, Annelies van Loon ${ }^{1,2}$, Kathryn A. Dooley ${ }^{3}$, Ralph Haswell ${ }^{4}$, Robert G. Erdmann²,5, \\ Emilien Leonhardt ${ }^{6}$ and John K. Delaney ${ }^{3}$
}

\begin{abstract}
The initial steps that Johannes Vermeer took to create Girl with a Pearl Earring (c. 1665) are, partially or completely, hidden beneath the painted surface. Vermeer's painting technique involved applying underlayers that vary in colour and thickness, on top of which he applied the upper paint layer(s). To investigate the painting's genesis, the Girl was examined using non-invasive scientific imaging as part of the project The Girl in the Spotlight (2018). This was complemented by the re-examination of existing paint cross-sections using microscopic analytical techniques, including focused ion beam-scanning transmission electron microscopy (FIB-STEM). The weave of the canvas, visible in the X-radiograph, was examined using a new computer-assisted thread-level canvas analysis algorithm to measure the thread spacing and thread angles. The canvas was primed with a warm light grey ground, although probably not by Vermeer himself. The tinted ground provided neutral base tone upon which he began to lay in areas of light and shade in his composition, and some outlines around the figure. Multispectral infrared reflectography( MS-IRR) images in four spectral bands spanning the spectral range from 900 to $2500 \mathrm{~nm}$ were collected of the painting at high spatial resolution $(50 \mu \mathrm{m} /$ pixel). Visible 3D digital microscopy visualised the underlayers where Vermeer left them visible around the perimeter of the figure as a contour, and where the upper paint layers are thin. These infrared reflectograms and visible micrographs identified three distinct preparatory phases of Girl with a Pearl Earring: the ground, fine black outlines, and underlayers. Some pentimenti were also detected, including a change in the position of her ear. The combination of examination methods showed that the materials beneath the surface played an important role in establishing the three-dimensional space, fall of light, and the eventual colour in different areas of the painting.
\end{abstract}

Keywords: Canvas, Ground, Underlayer, Sketch, MS-IRR, 3D digital microscopy, SEM-EDX, FIB-STEM

\section{Introduction}

Johannes Vermeer's Girl with a Pearl Earring (c. 1665), from the collection of the Mauritshuis, the Hague, is so iconic that the public may not recognise it as a low relief three-dimensional object. Layers beneath the surfacecanvas, ground and underlayers-play an important role

\footnotetext{
*Correspondence: a.vandivere@mauritshuis.nl

${ }^{1}$ Conservation Department, Mauritshuis, Plein 29, 2511 CS The Hague,

The Netherlands

Full list of author information is available at the end of the article
}

in the painting's appearance but are, partially or completely, hidden beneath the surface.

Girl with a Pearl Earring was examined in 2018 by a team of conservators and scientists as part of the project The Girl in the Spotlight [1]. Three of the research questions posed during the project were related to the layers beneath the surface: (1) What steps did Vermeer take to create the painting, including his choice of canvas and ground? (2) What can we find out about layers beneath the surface? (3) Which techniques did Vermeer use to create subtle optical effects, including the transition between light and shadow? 
To address the first question, the canvas weave was analysed using computer-assisted thread-level canvas analysis, and the results were compared to those from an earlier study [2]. To answer the second question, the painting was examined using several non-invasive imaging techniques to provide information about the painted underlayers. These methods included high spatial resolution multispectral infrared reflectography (MS-IRR: 900-2500 nm) and high-resolution visible 3D (Z-stack) microscopy. IRR is known to be useful at visualising painted underlayers and underdrawing that contain infrared-absorbing materials, such as carbon black or umber. Recent advances in both camera technology and the collection of IRR images in narrow spectral regions has been shown to better visualise painted layers below the surface when compared to IRR images collected in comparatively broader spectral regions [3]. Since the 1980 IRR investigation-done with a vidicon by van Asperen de Boer and Wheelock [4] - found evidence for dark underlayers in passages of the painting, there was interest to further investigate the underlayers with new high-resolution infrared reflectography.

High-resolution 3D digital microscopy can provide insights about the colour of the underlayers, and how they were applied beneath areas where the upper paint layers are thin or absent. While these images can visualise portions of the underlayers, they give limited information about the pigments used within them. The identification of pigments in various layers was obtained from the analysis of cross-sections, although the information is localised to a discrete area and may not be representative of the pigment distribution across the entire painting. Cross-sections obtained during the 1994 restoration treatment [4] were re-examined for the 2018 study using several analytical techniques, including: scanning electron microscopy-energy dispersive $\mathrm{X}$-ray analysis (SEM-EDX) and focused ion beam-scanning transmission electron microscopy (FIB-STEM). New information about the pigment composition, thickness, colour and stratigraphy of the ground and underlayers was obtained at discrete locations. FIB-STEM allowed parts of the samples to be examined at greater spatial resolution, distinguishing individual (small) particles, and determining their elemental composition more precisely without influence from the surrounding bulk of the sample.

The comparison of results from all these methods offer the potential for a more complete understanding of the preparatory layers in Girl with a Pearl Earring. The role of the underlayers-in this case, the underlayers beneath the Girl's jacket-is discussed to demonstrate how Vermeer established the fall of light and shade, and subtle colour nuances by exploiting the visual effects from this dark paint beneath the surface. This helps to answer the third research question posed by the Girl in the Spotlight project: Which techniques did Vermeer use to create subtle optical effects, including the transition between light and shadow? The role of the underlayers in other areas of the painting are discussed in greater detail in other articles in this digital volume [5-8].

\section{Experimental methods \\ Non-invasive imaging $X$-radiography}

X-radiograph films in the Conservation Department of the Mauritshuis show the condition of the painting before the 1994 restoration treatment. The X-radiographs were scanned into a computer using an Epson Expression $10000 \mathrm{XL}$ scanner at a spatial sampling of $42.3 \mu \mathrm{m} /$ pixel (600 pixel/inch).

New X-radiographs were made using an Andrex BW85 $\mathrm{X}$-ray tube, with a maximum $80 \mathrm{kV}$ output. The entire surface of the painting was captured on four films (Agfa Structurix D7) with two settings: $30 \mathrm{kV}, 2.4 \mathrm{~mA}, 1 \mathrm{~min}$ $20 \mathrm{~s}$, with $0.3 \mathrm{~mm} \mathrm{Al} \mathrm{filter} \mathrm{and} 70 \mathrm{kV}, 2.4 \mathrm{~mA}, 15 \mathrm{~s}$, with $0.3 \mathrm{~mm} \mathrm{Al}$ filter. A detail was captured on one film at: $8 \mathrm{kV}, 2.6 \mathrm{~mA}, 3 \mathrm{~min}$. The X-rays were digitised at a spatial sampling of $42.3 \mu \mathrm{m} /$ pixel on an Epson 10000XL scanner.

\section{Computer-assisted thread-level canvas analysis}

The canvas weave pattern in the X-radiograph digital images was analysed using an updated algorithm to the one previously developed by Van der Maaten and Erdmann [9]. To perform thread-level canvas analysis, the algorithm identifies the trajectories of each of the individual threads in the $\mathrm{X}$-radiograph (digitised at a spatial resolution of $42.3 \mu \mathrm{m} /$ pixel). From this collection of thread trajectories, the algorithm extracts centre-to-centre distances between threads and the angle of the thread relative to the $X$-axis at each point along its length.

This algorithm includes the following key steps: 1) extracting canvas features from the digital X-radiograph image, utilising the fact that there is a variation of the optical thickness of the radiopaque ground layer due to the physical thickness difference in the ground that fills in gaps between the threads and covers the threads, 2) training and deploying a Bayesian machine-learning model that automatically detects thread centres based on these features, and 3) using the response of this detector to trace each thread in the canvas. The result can be visualised as thread spacing maps (Fig. 2a, b) and thread angle maps (Fig. 2c, d).

Multispectral infrared reflectography (MS-IRR, 900-2500 nm) Digital infrared images in the $900-1100 \mathrm{~nm}$ range were made using a Hasselblad 503CX camera body, with a converted camera back: Leaf Credo 80 WS (wide-spectrum) 
with an $80 \mathrm{MP} C \mathrm{CD}$ sensor, sensitive up to $1100 \mathrm{~nm}$. The exposure settings were: ISO 35, exposure time 1/60 s, and aperture $\mathrm{f} / 11$. The lens is a Carl-Zeiss $120 \mathrm{~mm}$ macro-planar lens. A Heliopan digital RG 1000 filter, which blocks the visible and infrared wavelengths below $900 \mathrm{~nm}$, was placed in front of the lens. The light sources used were Broncolor strobes and $640 \mathrm{~W}$ halogen modelling lights with two P70 reflector shells. The whole painting was photographed both as a single image (output 16-bit, eciRGB v2 ICCv4, 430 MB $7760 \times 9300$ px) corresponding to an on-painting spatial resolution of $50 \mu \mathrm{m} / \mathrm{pixel}$, and at a higher resolution of $16 \mu \mathrm{m} /$ pixel in the form of sixteen images (output 16-bit, eciRGB v2 ICCv4, 4.5 GB $25,850 \times 31,000 \mathrm{px})$. Capture One software was used to capture images, using a custom camera profile, and creating an LCC-lens profile, output 16-bit eciRGB v2 ICCv4. BasICColor input 3 was used to create a custom camera profile. Photoshop CC was used for end (final) corrections.

Multispectral infrared reflectography in the 1100$2500 \mathrm{~nm}$ range was done with a near infrared optimised high spatial resolution infrared camera outfitted with broadband interference bandpass filters (J: 1100$1400 \mathrm{~nm}, \mathrm{H}: 1500-1800 \mathrm{~nm}$, and 1900-2500 nm). The camera consisted of a $50 \mathrm{~mm}$ EFL F/D 2.3 lens (Stingray, $\mathrm{NH}$ ) optimised for the spectral range from 1000 to $2600 \mathrm{~nm}$ and a high definition infrared camera (model 912, IRCameras, CA) having an indium antimonide (InSb) detector array of $1280 \times 1024$ pixels. The spatial sampling was $50 \mu \mathrm{m} /$ pixel at the painting. The resulting images were spatially mosaicked by registering with a visible light image of the painting using a previously published algorithm [10].

\section{Stereomicroscopy}

The painting was examined at up to $40 \times$ magnification using a Zeiss Universal S2 stereo-microscope to characterise the painting sequence.

\section{High-resolution visible 3D digital microscopy}

The painting was examined using the Hirox RH-2000 $3 \mathrm{D}$ digital microscope on a motorised 'bridge' stand with a $500 \times 500 \mathrm{~mm}$ automatic motorised $X Y$ stage (200 nm steps). The 'bridge' stand was made specifically for the Girl in the Spotlight project to accommodate the painting, which was placed horizontally. The microscope zoom lens MXB-5000REZ was mounted on the Hirox FB-E $Z$-axis block with $30 \mathrm{~mm}$ motorised movement (50 nm steps). It can achieve spatial sampling from $4.4 \mu \mathrm{m} /$ pixel $(35 \times)$ down to $0.03 \mu \mathrm{m} /$ pixel $(5000 \times)$, and for this painting, the range $4.4 \mu \mathrm{m} /$ pixel $(35 \times)$ to $0.22 \mu \mathrm{m} /$ pixel $(140 \times)$ was used. The illumination used for most images was mixed: raking light
(100\% light intensity) and ring light/dark field (10\% light intensity). At $35 \times$ magnification $(4.4 \mu \mathrm{m} /$ pixel $)$, the tile size is $8.5 \times 5.28 \mathrm{~mm}$. At $140 \times(1.1 \mu \mathrm{m} / \mathrm{pixel})$, the tile size is $2.1 \times 1.31 \mathrm{~mm}$.

The complete painting was automatically scanned at a sampling resolution of $4.4 \mu \mathrm{m} /$ pixel with a $30 \%$ overlap: the microscope acquired a series of images in the $Z$-axis, capturing each focus layer and then combining them in one single all-in-focus image (also known as $Z$-stacked or extended depth of field). The microscope then moved in the $X$ and/or $Y$ direction to the next tile, and the process automatically started again, so that a total of 9100 $Z$-stacked images were acquired in approximately $14 \mathrm{~h}$. For each tile, a $Z$-stacked image as well as a TDR file (Hirox 3D file format) were created, which included true colours and altitude, so that the $X Y Z$ coordinates are registered for each pixel. All of the scans at resolutions of $1.1 \mu \mathrm{m} /$ pixel and at $0.22 \mu \mathrm{m} /$ pixel (both with a small depth of field) provided very detailed $Z$ information that could be used for 3D measurements. Additionally, 9 selected areas were acquired at 140× (resolution of $1.1 \mu \mathrm{m} /$ pixel), creating high resolution 3D stitching.

The Hirox RH-2000 main unit software (which was modified specifically for this project) was used to calibrate and display a live image, then to create full auto $Z$-stacked 3D data and to program a fully automatic $X Y Z$ acquisition with selectable overlap (offline tiling without any pixel size limit in the full scan).

The final results of those scans were twofold: (1) an allin-focus stitched image of the full painting at approximately 10 billion pixel resolution using the $4.4 \mu \mathrm{m} /$ pixel resolution images, and (2) 9 key areas captured as allin-focus super high resolution stitched areas at $1.1 \mu \mathrm{m} /$ pixel. In the $1.1 \mu \mathrm{m} /$ pixel details, one can zoom to specific areas with very high level of detail, and individual pigment particles can be visualised and measured.

\section{Micro-sample analysis \\ Paint micro-samples}

During the conservation treatment of Girl with a Pearl Earring in 1994, microscopic samples from the Girl's jacket were mounted as cross-sections: sample 25 from a light part at the front, sample 11 from the shadow over her shoulder, and sample 14 that presumably came from a dark part of her jacket (a dislodged fragment where the precise original location is unknown) [1]. They were embedded in Poly-pol PS230, a two-component polyester mounting resin (Poly-Service Amsterdam, the Netherlands). As part of the 2018 Girl in the Spotlight project, these samples were re-examined using several analytical techniques, including light microscopy, SEM-EDX and FIB-STEM. 


\section{Light microscopy (LM)}

The cross-sections were photographed in 2008 using a Leica DM2500 light microscope equipped with a Leica DFC490 digital camera. In 2018, a Zeiss Axio Imager. A2m microscope equipped with a Zeiss AxioCam MRc5 digital camera was used to re-examine the polished cross-sections and to capture images at spatial resolutions of $0.54 \mu \mathrm{m} /$ pixel $(100 \times), 0.27 \mu \mathrm{m} /$ pixel $(200 \times)$ and $0.11 \mu \mathrm{m} /$ pixel $(500 \times)$ in bright field, dark field and ultraviolet (UV-A).

\section{Scanning electron microscopy-energy dispersive X-ray analysis (SEM-EDX)}

SEM backscattered-electron images of the uncoated samples were acquired at the Ateliergebouw (Studio Building), Amsterdam, with an FEI NovaNano SEM 450 variable pressure electron microscope at low vacuum $(70 \mathrm{~Pa})$, and an accelerating voltage of $20 \mathrm{kV}$. The SEM was equipped with a Thermo EDX system to yield elemental composition of the pigments within the layers.

EDX mapping was done at Shell Technology Centre Amsterdam (STCA) using a JEOL 7000F high-vacuum SEM coupled to a ThermoFisher NSS EDX system with dual $30 \mathrm{~mm}^{2}$ silicon drift detectors. The samples were carbon-coated (Leica ACE600 nominally $15 \mathrm{~nm}$ thick) prior to EDX mapping to improve surface conductivity. All the samples were mapped using spectral imaging at either $500 \times$ or $1000 \times$ magnification. Each map consists of $256 \times 202$ pixels and the collection time was typically $30 \mathrm{~min}$. The step size of the images was $1.04 \mu \mathrm{m} /$ pixel and $0.52 \mu \mathrm{m} /$ pixel for the $500 \times$ and $1000 \times$ images, respectively.

\section{Focused ion beam-scanning transmission electron microscopy (FIB-STEM)}

The combination of STEM and EDX was used to 'map' the element distribution in thin sections prepared from painting cross-sections using the FIB. The thin sections were prepared using the standard ex situ lift-out method [11]. This involves cutting out a cross-section specimen from its substrate and transferring this onto a thin support membrane using a micromanipulator. In the case of paint cross-sections this means that the section can be milled directly from the bulk sample. All thin sections were prepared using a FEI Helios dual beam system. The rough milling was done using a beam current of 21 $\mathrm{nA}$ and for the final polishing it was $93 \mathrm{pA}$. The tilt offset was $0.6^{\circ}$. The nominal thickness of the sections was $200 \mathrm{~nm}$ with a width of $20 \mu \mathrm{m}$ and height of $8 \mu \mathrm{m}$.

Spectral images were made at magnifications ranging from $20,000 \times$ up to $24,0000 \times$ with an accelerating voltage of $200 \mathrm{keV}$. Each map consists of $512 \times 512$ pixels and the collection time was typically between 5 and $15 \mathrm{~min}$.
The spatial resolution of the images was $26 \mathrm{~nm} /$ pixel and $2.2 \mathrm{~nm} /$ pixel for the $20,000 \times$ and $24,0000 \times$ images, respectively. The microscope used for this work was a JEOL2800 with two Centuro EDX silicon drift detectors. The measurements were made at the Shell Technology Centre Amsterdam (SCTA).

\section{Results \\ Canvas weave}

The support of Girl with a Pearl Earring is a dense medium-weight canvas with a plain weave, which is visible on an X-radiograph (Fig. 1). The average thread spacing of the horizontal threads is $0.68 \pm 0.12 \mathrm{~mm}$, corresponding to a thread count of $14.8 \pm 2.7$ threads $/ \mathrm{cm}$. The vertical threads have an average centre-to-centre spacing of $0.68 \pm 0.14 \mathrm{~mm}$, corresponding to a thread count of $14.6 \pm 3.0$ threads $/ \mathrm{cm}$, as determined by digital thread counting. The data from computer-assisted canvas analysis was used to make maps from the digitised $\mathrm{X}$-radiograph, showing variations in the canvas threads in both horizontal and vertical directions. The thread spacing maps show how the density of the threads varies across the canvas; when the number of threads per centimetre varies from the average, it is assigned a specific colour, creating a kind of 'barcode' for the painting (Fig. 2a, b). The more uniform spacing of the horizontal threads, compared to the wide streaks of closely- and widely-spaced threads in the vertical direction, indicates that the vertical threads are the weft threads and the horizontal threads are the warp threads.

The thread angle maps show deviations in the angle of the threads, especially the cusping around the edges (Fig. 2c, d). The wave-shaped distortions are spaced approximately 5-7 $\mathrm{cm}$ apart. They extend more than $5 \mathrm{~cm}$ into the picture plane on all sides, indicating that they are primary cusping: points where the reinforced edges of the canvas were laced onto a larger framework using cord or string before the ground layer was applied [12]. The string could be tightened to keep the canvas taut during sizing of the canvas and application of the ground. Additionally, there is evidence of secondary cusping of the horizontal threads on the upper edge of the painting (at approximately $\mathrm{x}=12 \mathrm{~cm}, 24 \mathrm{~cm}$, and $35 \mathrm{~cm}$ ); these correspond to points where the pre-stretched canvas was attached to a smaller framework (strainer) [12]. The vertical thread angle also exhibits evidence of socalled 'weft snakes' [13]: an anomaly occurring in the weft threads. This is consistent with the identification of the vertical direction as the weft direction from the thread spacing maps.

The thread count from the recent thread-level canvas analysis is similar to the findings of the Counting Vermeer project [2]. By performing digital thread counting 

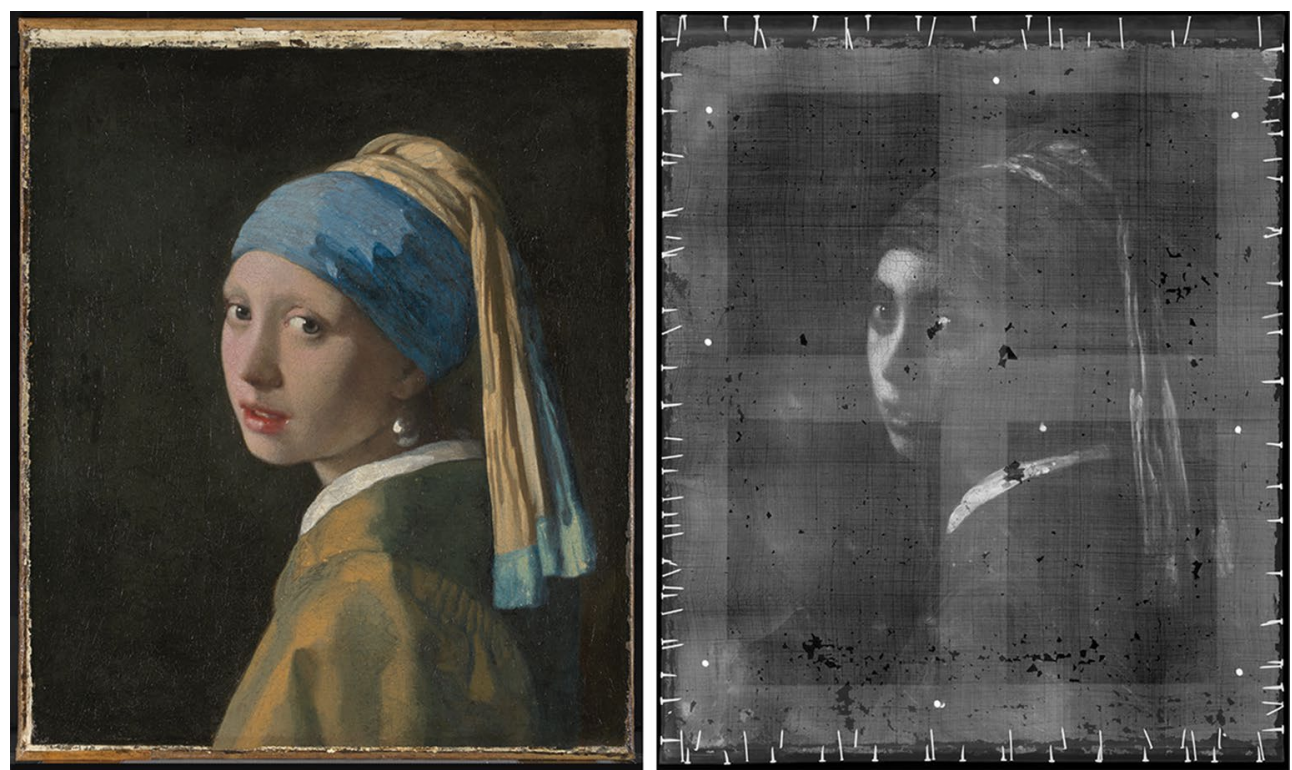

Fig. 1 Johannes Vermeer, Girl with a Pearl Earring, c. 1665. MH670, Mauritshuis, The Hague. a Visible light photograph. b X-radiograph. René Gerritsen Art and Research Photography

on old X-radiograph films of Girl with a Pearl Earring (X-radiographs made before the 1994 treatment, precise date unknown), Johnson and Sethares determined that the average thread density is $14.66 \pm 1.46$ (horizontal) $\times 14.50 \pm 1.58$ (vertical) threads $/ \mathrm{cm}$. They identified cusping extending more than $5 \mathrm{~cm}$ into the painting on all four sides, but did not distinguish between primary and secondary cusping. Furthermore, they did not identify weft snake indicators.

The discussion section of this paper describes how the canvas of Girl with a Pearl Earring fits within Vermeer's oeuvre.

\section{Ground layer}

Visual examination of the remains of the original tacking margins-folded out around all four sides-showed that they are not painted, but only covered with the light warm greyish ground [14]. This suggests that the ground was applied while the canvas was on a large framework, then moved to a strainer with smaller dimensions before Vermeer started painting [12]. On the X-radiograph image or film, faint curved strokes near the bottom edge of the painting show where the ground is slightly thicker; this suggests that the ground had the consistency of a thick paste, and was applied with a curved primer's knife $[14,15]$.

The ground of Girl with a Pearl Earring was found to be about $100 \mu \mathrm{m}$ thick (in one sample from the edge, up to $200 \mu \mathrm{m}$ thick), estimated from the 18 cross-sections that were re-examined as part of this study [1].
The composition of the ground was first investigated as part of Hermann Kühn's 1968 survey of pigments and grounds in paintings by Vermeer [16]. Samples analysed using light microscopy and SEM-EDX in the 1990s [4] found that the ground of the Girl consists of chalk, lead white, red and yellow iron oxide (earth) pigments, and a very fine dark pigment. The dark pigment was described by Groen et al. [4] as "a little very fine carbon black, possibly lamp black." Kühn [16] suggested the presence of umber, lead white and chalk in the ground using emission spectrographic analysis and light microscopy of a cross-section from the right edge. For the current study, cross-sections were re-analysed using SEM-EDX and FIB-STEM. The 2018 analysis of two samples (14 and 34) confirmed that some of the dark particles in the ground are umber - a dark brown pigment containing iron oxide and manganese oxide-which had previously been suggested by Kühn [16] but not found by Groen et al. [4]. SEM-EDX analysis of these dark particles in sample 14 detected iron and manganese (results not shown). Based on the techniques used in this study, the presence of a very fine carbon black could neither be confirmed nor ruled out.

The large electron interaction volume in the bulk sample used for SEM-EDX means that the EDX map resolution is a few micrometres at best. This limitation is, by definition, removed when a thin section is prepared with the focused ion beam (FIB): a thin lamella is removed from a specific location in an embedded crosssection and transferred to a membrane (Fig. $3 \mathrm{~d}-\mathrm{g}$ ). 

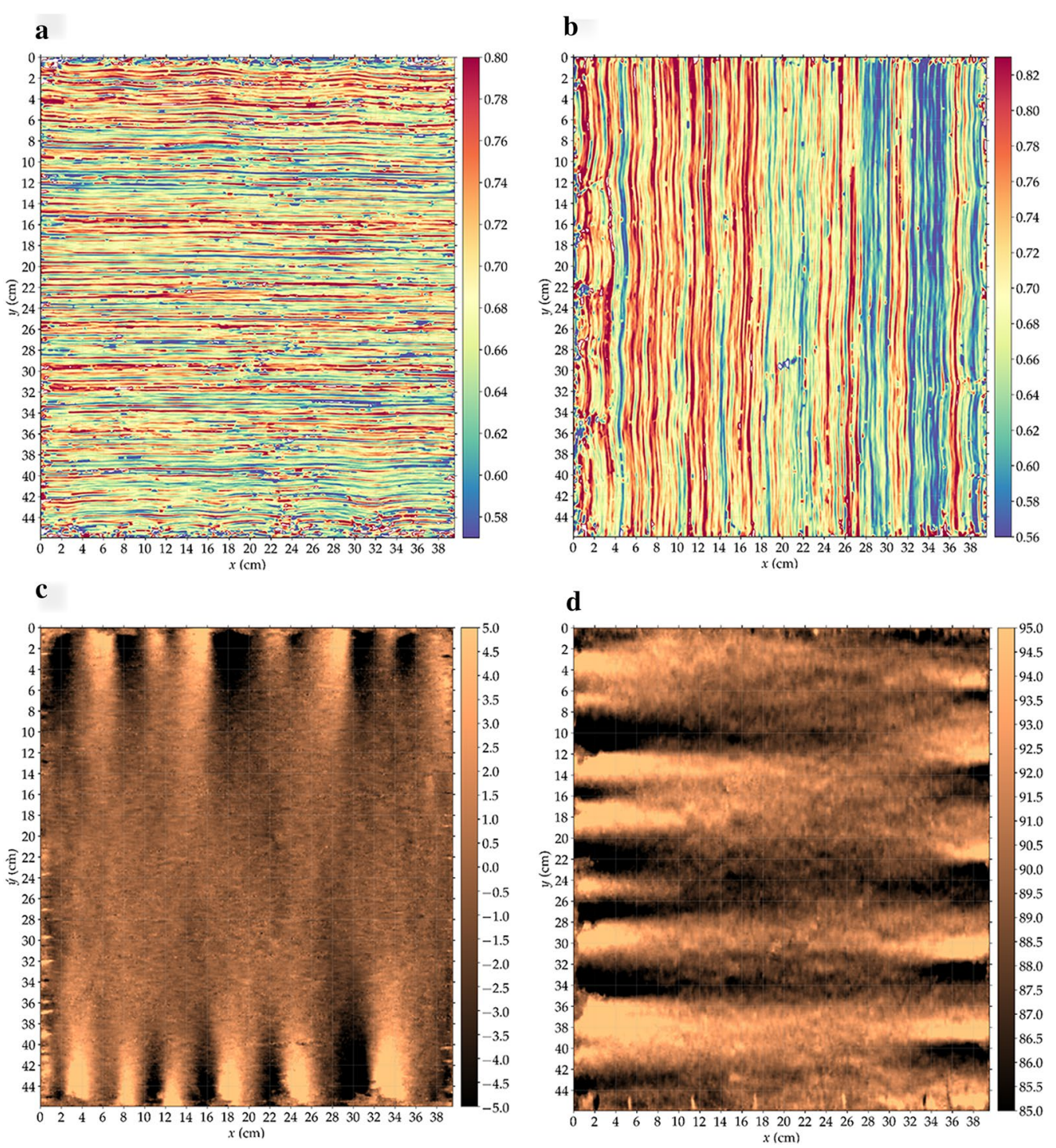

Fig. 2 Computer-assisted thread-level canvas analysis (from 2018 X-radiograph made by René Gerritsen Art \& Research Photography). a Horizontal thread spacing $(\mathrm{mm})$. b Vertical thread spacing $(\mathrm{mm})$. $\mathbf{c}$ Horizontal thread angle (degrees). $\mathbf{d}$ Vertical thread angle (degrees)

Using scanning transmission electron microscopy (STEM) each lamella is examined at a very high magnification (here $20,000 \times$ ) and elements are mapped with the EDX detector (Fig. 3h). The element map resolution is now much closer to the size of the electron beam, which was nominally $2 \mathrm{~nm}$. In practise, there will still be some beam broadening due to the finite thickness of the sample, so we estimate the resolution of STEMEDX map to be of the order of $5 \mathrm{~nm}$, which is the pixel size used for the mapping data. The ability to probe the structure of the samples at this length scale is demonstrated in Fig. 3h, i, where a multitude of features are visible at the sub- $100 \mathrm{~nm}$ scale that were not possible to resolve in the SEM-EDX maps.
The major components of the ground were also analysed with FIB-STEM. The STEM-EDX map at a magnification of $20,000 \times$ indicates that the largest proportion of the ground is chalk (in blue in Fig. 3h), with a smaller amount of lead white (in red in Fig. 3h). The way that the lead white fills the voids between the large chalk particles showed that the ground layer is very compact. The varying particle size of the lead white in the ground, with its distribution as lumpy aggregates and small particles is consistent with pigment made according to the so-called Dutch stack process [17].

The results of re-analysis of cross-sections from the ground layer of Girl with a Pearl Earring found chalk, lead white, and umber. Also, light microscopy suggests 

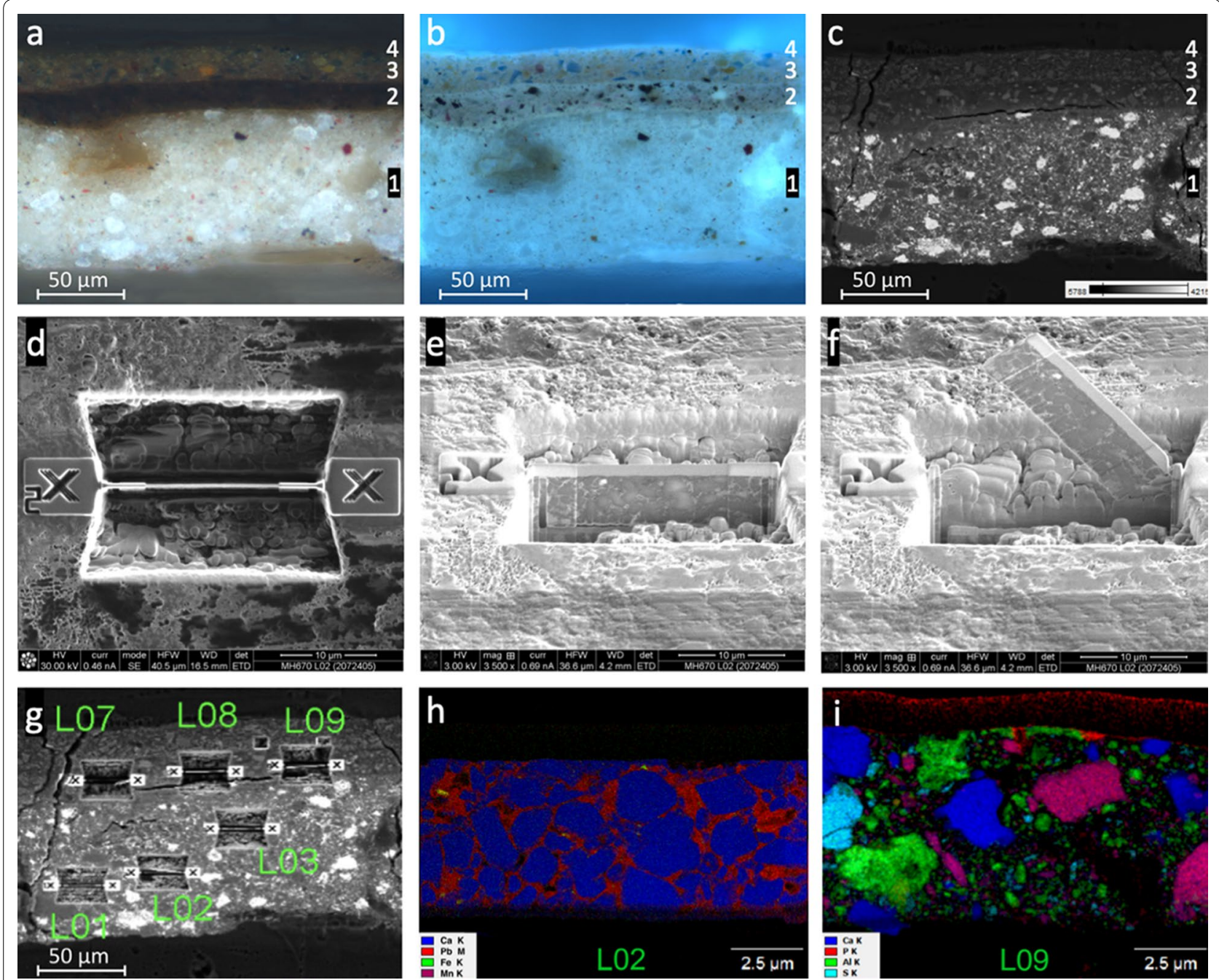

Fig. 3 Examination and analysis of sample 14 from the dark part of the Girl's jacket (exact location unknown), mounted as a cross-section. a Light microscopy, bright field. 1: ground, 2: underlayer, 3: paint layer, 4: varnish, b Light microscopy, UV fluorescence. c SEM backscatter image. d-f Preparation of lamella using FIB. $\mathbf{g}$ Backscatter image showing FIB lamella locations. $\mathbf{h}$ STEM-EDX overlay of FIB lamella L02 from the ground: Ca (blue), Pb (red), Fe (green), Mn (magenta), i STEM-EDX overlay of FIB lamella L09 from the dark underlayer: Ca (blue), P (red), Al (green), S (cyan)

the presence of yellow and red earth pigments, and carbon black [4].

\section{Underlayers, outlines and pentimenti revealed} by multispectral infrared reflectance imaging (MS-IRR)

In this paper, underlayers are defined as: paint layers that Vermeer applied at a preparatory stage, which were left to dry before the upper layer(s) of paint were applied. Usually an underlayer is hidden beneath the surface, but in some areas it may have been left exposed, or thinly covered by surface layers. In this context, contours are defined as the border between different parts of the composition, where one colour approaches another [18].

High resolution multispectral infrared reflectography (MS-IRR) $[19,20]$ was done in order to obtain a more complete visualisation of how the dark underlayers were applied. MS-IRR ( $50 \mu \mathrm{m} /$ pixel) was done using two camera systems, the first of which consisted of a Si CCD digital camera and filter that set the spectral sensitivity to $900-1100 \mathrm{~nm}$. In the resulting image (Fig. $4 \mathrm{~b}$ ), some infrared-absorbing brushstrokes beneath the surface were revealed, but mainly in areas where the top paint layers are optically quite thin. Within the Girl's headscarf and yellow jacket, some folds depicted in the upper paint layers appear light in infrared photography, in contrast to some infrared-absorbing paint of the underlayers which appear dark. However, in most of the painting, the infrared-absorbing brushstrokes below the surface remain partially or totally obscured by the optically thicker surface paint. 

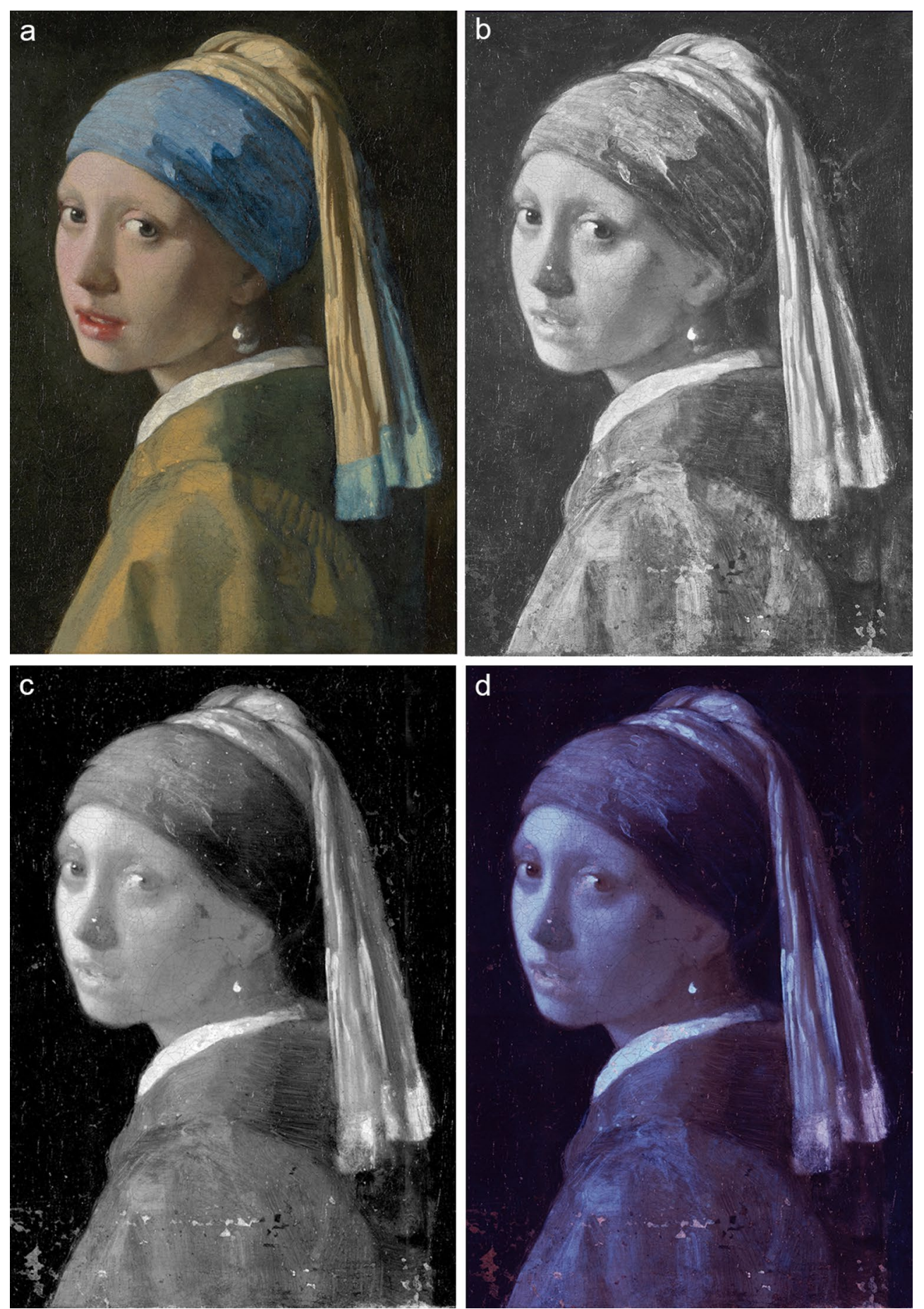

Fig. 4 Details of the Girl with different infrared imaging methods: a Visible light image. René Gerritsen Art \& Research Photography. b MS-IRR infrared image (900-1100 nm), single image. René Gerritsen Art \& Research Photography. c MS-IRR infrared image (1900-2500 nm). d MS-IRR infrared false colour composite image (red 1900-2500 nm, green 1500-1800 nm, blue 1100-1400 nm)

The spectral range was extended out towards $2500 \mathrm{~nm}$ with the goal of making the features within the dark underlayers more visible. This was done using an InSb infrared camera system with spectral sensitivity from 1000 to $2500 \mathrm{~nm}$, with images collected in three spectral bands (1100-1400 nm, 1500$1800 \mathrm{~nm}$, and 1900-2500 nm) and also at the same high resolution $(50 \mu \mathrm{m} / \mathrm{pixel})$. The success of this approach 
relies in part on the increased transparency of pigments in the 1000-2500 $\mathrm{nm}$ spectral region, owing to the decrease in the intensity of the absorption coefficient of electronic transitions of many artists' pigments. It also relies on the decrease in the amount of light scattering due to the high optical refractive index of the pigment particles. This greatly improves the transparency of pigments such as lead white, which lack any electronic absorption bands in the visible and infrared $(400-2500 \mathrm{~nm})$ [3]. While traditionally infrared reflectography is collected in one broad spectral band, recent research has shown that collecting images in narrower spectral bands can help to isolate different phases of the painting process: for instance, to distinguish a preparatory drawing-often applied with an infrared-absorbing material-from the partially penetrated paint layers [20]. These narrower spectral bands $(3-300 \mathrm{~nm})$ also allow for specific pigments to be separated from each other within the paint layers [3]. Furthermore, the high spatial resolution can reveal complete brushstrokes in the paint of the lower layers, making it possible to identify early phases in the painting process. By spatially registering these MS-IRR spectral images with the visible light image, the relationship between the underlayers and the final painted composition can be unpacked.

Comparing the MS-IRR image from 900 to $1100 \mathrm{~nm}$ (Fig. 4b) with the image from 1900 to $2500 \mathrm{~nm}$ (Fig. 4c) shows the improved penetration at longer wavelengths, as expected. The difficulty with monochromatic IRR images is the ability to separate the underlayer from partially penetrated upper paint layers. This can be more readily done by viewing a false colour composite image constructed from MS-IRR spectral images, with three colour channels corresponding to the latter three spectral bands (Fig. 4d). In this false colour image, areas that appear dark (black) are from paint that absorbs in all three spectral regions, and the coloured regions represent paint layers whose reflectance varies among the infrared spectral regions. Despite the fact that MSIRR can generally penetrate through pigments like lead white, some areas of the Girl-like her earring, collar and highlights in her clothing-appear light in the MSIRR images, indicating that they were applied thickly (red arrows in Figs. 5 and 8).

The MS-IRR false colour image reveals dark underlayers beneath parts of the Girl's jacket and blue headscarf that are meant to be in shadow. Beneath the right side of the blue headscarf, the pronounced brushstrokes in the underlayer-which appear dark in the false colour detail in Fig. 5 (green arrow) - are broad and were applied in a vaguely horizontal direction. Similar wide horizontal brushstrokes were detected beneath her yellow jacket (Fig. 6b). On the back of her shoulder, two vertical passages of horizontal brushstrokes overlap slightly in the middle; the right side is darker because it contains more carbon and/or umber. The front of her jacket that faces the light has similar vigorous brushstrokes in an underlayer, although they are lighter in intensity because they contain fewer infrared-absorbing pigments.

Vermeer made subtle changes or adjustments (pentimenti) during the painting process. Where the initial phase contains carbon black, some changes can be detected using MS-IRR. Vermeer shifted the Girl's ear upwards and repainted the earlobe and ear canal with a brown paint that does not absorb infrared (Fig. 5). He shifted the shadow along her jawline also to accommodate the new position of the ear, and straightened out the line between her cheek and the headscarf at the final painting stage (yellow arrows in Fig. 5). He also softened the definition of the back of the Girl's neck. Within each of the Girl's eyes, there is a small black dot visible in the MS-IRR false colour image (Fig. 7). Each dot is smaller and further to the left than the final position of the pupil, and is slightly overlapped by the white highlight that creates the reflection in her eye. Perhaps Vermeer intended for these to indicate the rough placement of the pupil or highlight, which he later shifted.

The MS-IRR false-colour image also reveals overlapping layers along the contour at the back of her headscarf (green arrow in Fig. 8). The edge of the yellow knotted fabric-from atop her head all the way along the 'tail' of the headscarf-was painted on top of the carbon black underlayer of the background. It is unclear whether this is a pentimento to make the headscarf wider, or whether Vermeer intentionally wanted the dark paint to be slightly visible in order to create a subtle transition where the headscarf meets the background.

MS-IRR also revealed another preparatory phase in the Girl's clothing: black outlines applied in short strokes with a fine brush (Fig. 8). These infrared-absorbing lines have so far only been detected around contours and folds, usually close to the perimeter of different coloured areas. Within the yellow part of her headscarf, the fine lines seem to have a 'beaded-up' quality (yellow arrows in Fig. 8), suggesting that either the paint droplets have resisted a dry layer beneath it, or they could have been applied using a brush that was not loaded with paint, so the lines 'skip' across the surface topology of a layer underneath. They seem to indicate both folds in fabric and the perimeter of the figure; however, Vermeer did not always follow these lines precisely when he eventually painted the final layers. These short black outlines are also visible in the MS-IRR images around the left perimeter of the Girl's yellow jacket and neck, and in the blue parts of her headscarf. They may also be present elsewhere in the painting, but the presence of other 

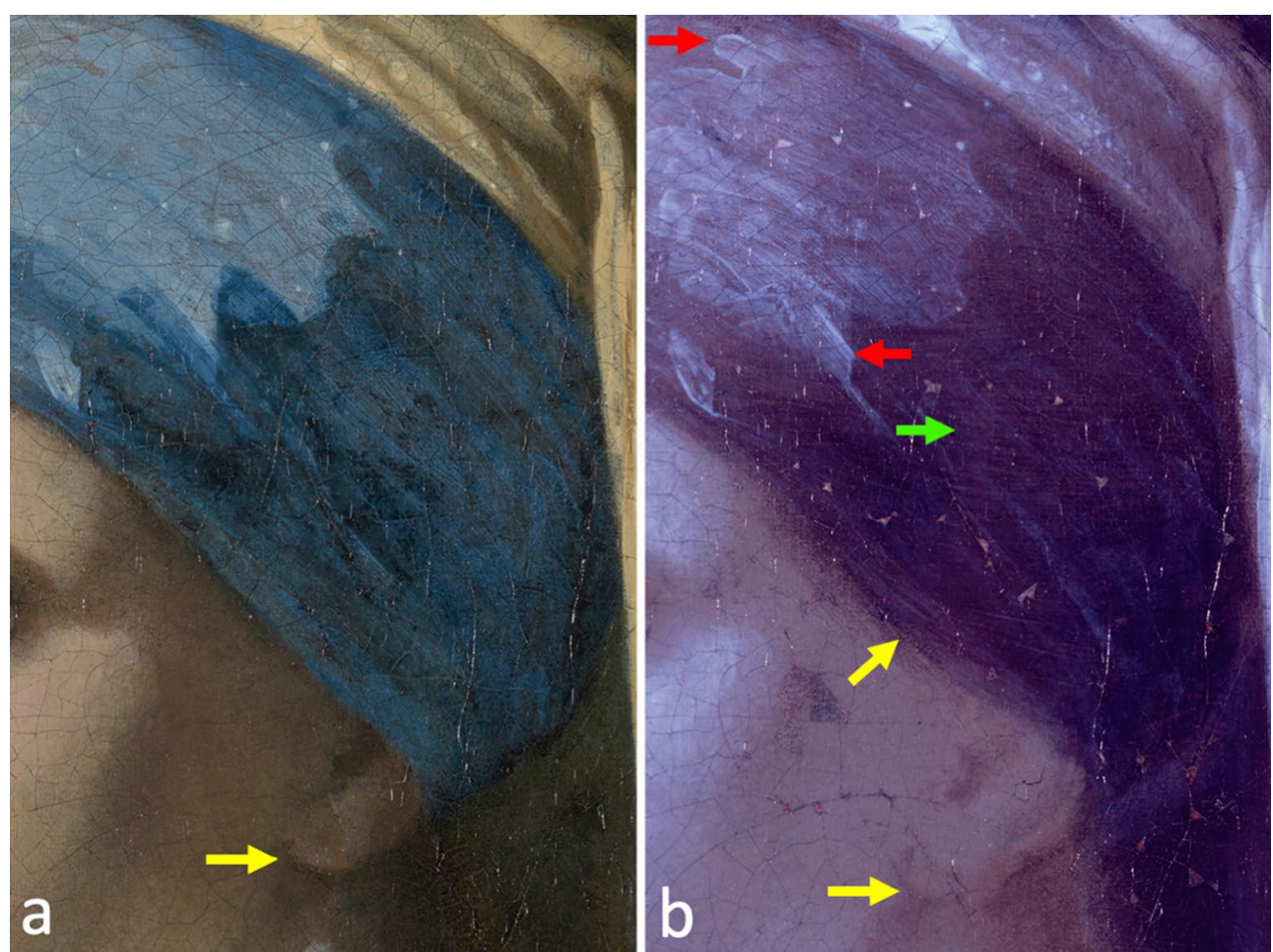

Fig. 5 Evidence for dark underlayers in the headscarf, and revision to the Girl's ear. a Visible light detail, b MS-IRR false colour detail, showing wavy strokes at the surface (red arrows), underlayers beneath the blue headscarf (green arrow), and an original lower position of the ear and headscarf (yellow arrows)

infrared-absorbing paints could hinder their detection. Some of these lines could be visualised under high magnification with the Hirox 3D digital microscope.

\section{Vermeer's use of underlayers to modulate light and shadow in the Girl's jacket}

The Girl's yellow jacket is an example of how Vermeer exploited the visual effect of the underlayer(s) to establish the difference between light and shade. The contrast between the front (lit) slide of the jacket and the back (shadow) is apparent in the visible light photograph (Fig. 6a). On the front of the jacket, the upper layer of paint has an opaque yellow-brown colour. On the Girl's back, and where the folds in the fabric are in shadow, the nuances of colour range from greenish to bluish. There, the upper layers of paint are thinner and more translucent, and the lower layers are slightly visible through them [4].

In 1994, Girl with a Pearl Earring underwent a restoration and conservation treatment at the Mauritshuis [14, 21]. Removing old retouchings revealed underlayers that were intended to be (partially) hidden beneath the surface, especially in her clothing. The conservators noted that the underlayer beneath her yellow jacket was lighter brown on the left (lit) side than on the right (shadow). At a later stage of the treatment, some of the damaged areas were retouched with thin, translucent paint; presumably this is close to Vermeer's original intention. In the midand dark tones, the underlayers would have been slightly visible though the upper layers to provide different colour nuances. Differences in the pigment composition and thickness of the underlayers in the light and shadow parts of the Girl's jacket were clarified by examining samples from each area, mounted as cross-sections (see below).

As part of the 2018 Girl in the Spotlight project, the whole surface of the painting was captured with the 3D digital microscope at a spatial resolution of $4.4 \mu \mathrm{m} /$ pixel (35 $\times$ magnification) and specific areas of interest were captured at $1.1 \mu \mathrm{m} /$ pixel resolution $(140 \times)$. At high magnification, the underlayer(s) are sometimes visible along the edges of cracks, or where the upper layer of paint is thin or abraded. Within her jacket, on the left side where the upper paint is light yellow in colour, the underlayer is a light warm-brown (Fig. 9a). In contrast, the shadows of the folds and towards the back of her garment, the underlayer is darker (Fig. 9b). Examination with the 3D microscope confirmed that the brown-black underlayer varies in tone. It also revealed the way that Vermeer created a soft contour between the figure of the Girl and the background. 

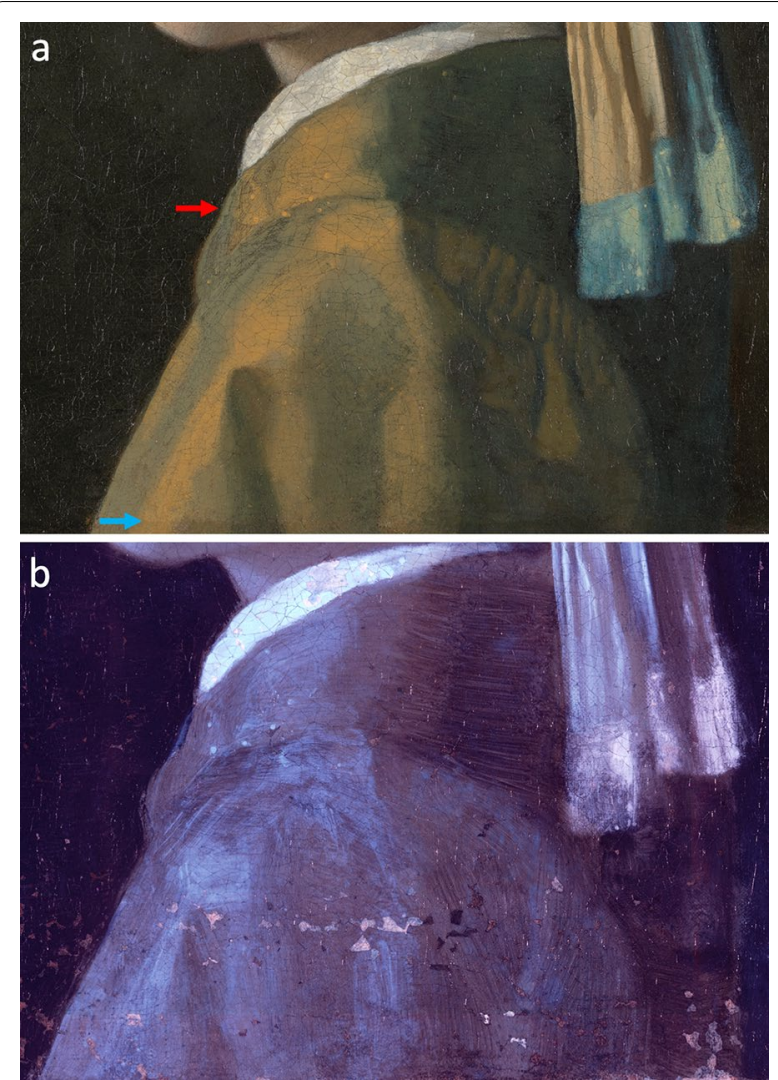

Fig. 6 a Visible light detail of the Girl's yellow jacket. René Gerritsen Art \& Research Photography. Location of 3D digital microphotograph (Fig. 10) indicated with red arrow. Location of sample 25 (Fig. 11) indicated with blue arrow. $\mathbf{b}$ MS-IRR false colour detail, showing dark underlayers in the Girl's jacket
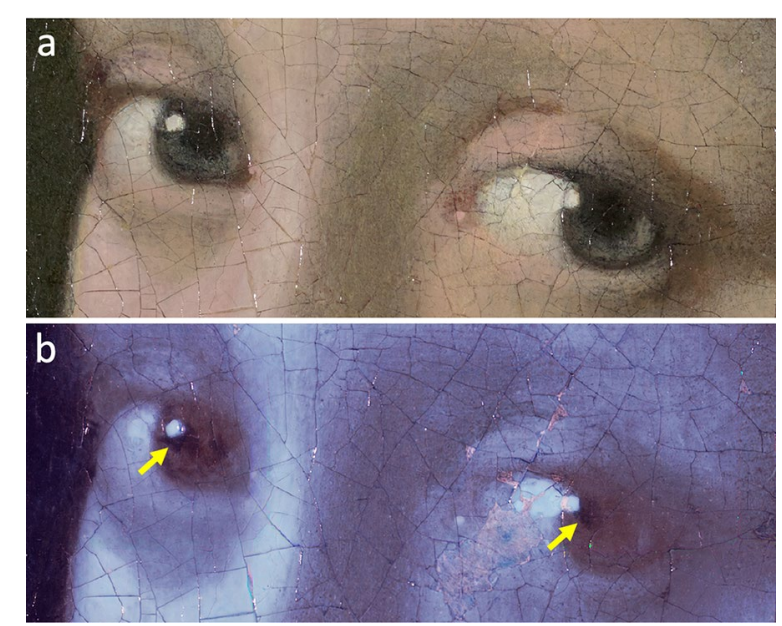

Fig. 7 Evidence for pentimenti in the Girl's eyes. a Visible light photograph. b MS-IRR false colour detail. Dark marks indicate possible earlier iris locations (yellow arrows)
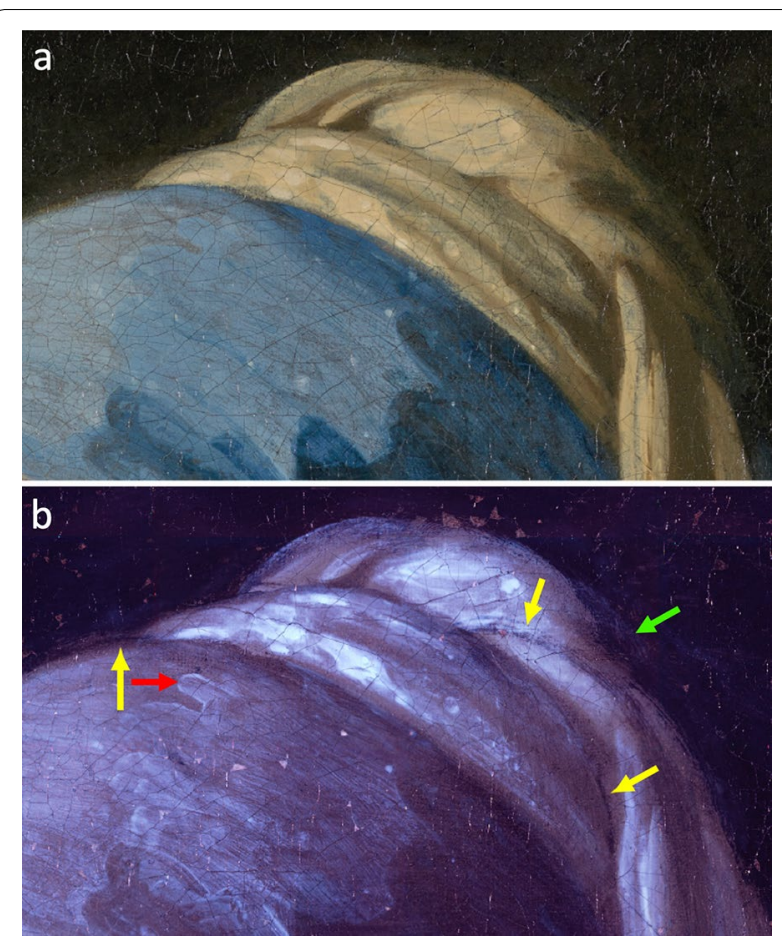

Fig. 8 Evidence for contours and fine black outlines in the top of headscarf. a Visible light photograph. b MS-IRR false colour detail. Wavy brushstrokes at the surface (red arrow), fine black outlines applied in a preparatory phase (yellow arrows), back of the headscarf applied on top of an infrared-absorbing layer (green arrow)

Under magnification, a 'gap' in the upper paint layers approximately 1-2 $\mathrm{mm}$ wide is visible between the edge of the figure (Fig. 10d) and the background (Fig. 10a). Within this gap, the brown underlayer has been left exposed (Fig. 10b); it extends slightly beyond the boundary of the figure that Vermeer established in the upper layers of paint. Some of the aforementioned fine black outlines (lines approximately $250 \mu \mathrm{m}$ wide) are also visible (Fig. 10c), although it is unclear whether the black lines were painted before or after the brown underlayer. By allowing the brown underlayer of the clothing to extend slightly beyond the perimeter of the figure and leaving it visible in the gap between the figure and the background, Vermeer created a diffuse contour that softens the transition.

\section{Chemical composition of the underlayers of the Girl's jacket}

In 1994, samples were taken from the light (sample 25) and dark (sample 14) parts of the Girl's jacket, mounted as cross-sections, and examined with light microscopy and SEM-EDX [4]. These samples were re-examined in 2018 using several analytical methods, including light microscopy and SEM-EDX. The new results from 

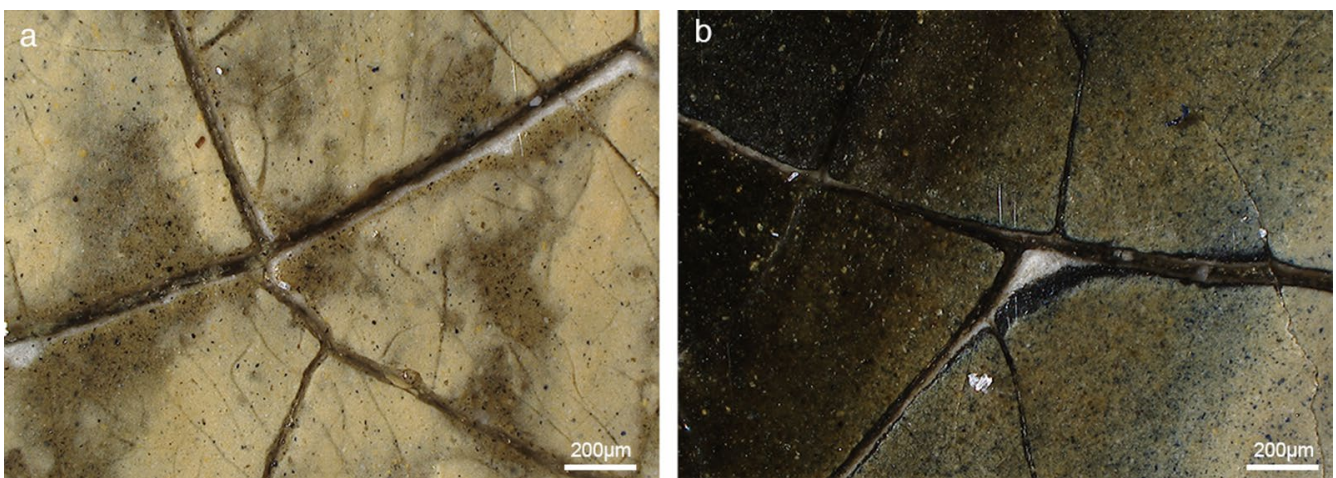

Fig. 9 3D digital microphotographs $(1.1 \mu \mathrm{m} /$ pixel) showing the underlayers beneath the upper layers of paint in the Girl's shoulder: a light area, $\mathbf{b}$ dark area. Hirox Europe, Jyfel

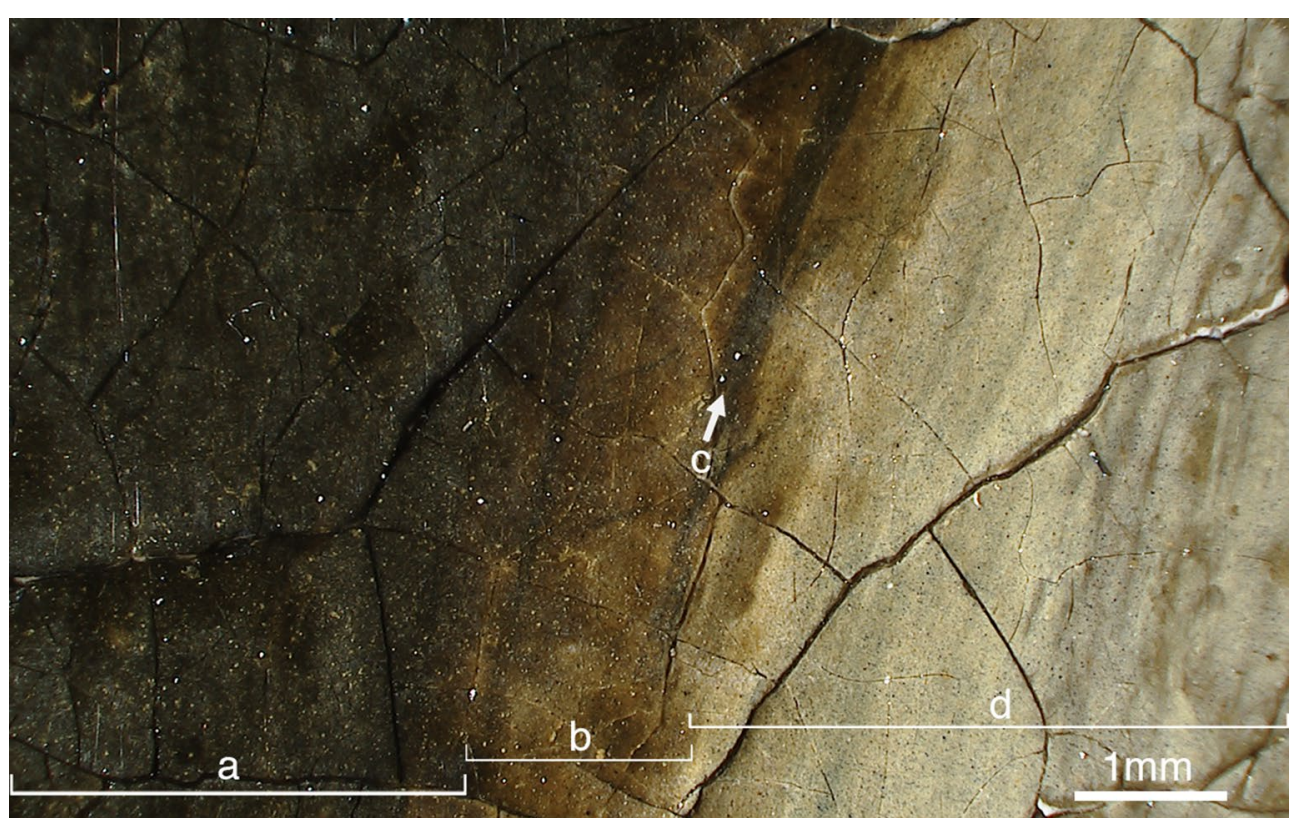

Fig. $103 D$ digital microphotograph $(4.4 \mu \mathrm{m} /$ pixel) of contour where the background (a) approaches the left side of the Girl's jacket (d). In the gap between them, the brown-black underlayer (b) and fine black outlines (c) are visible. Hirox Europe, Jyfel. Microphotograph location indicated with a red arrow on Fig. 6

the analysis of a cross-section from a light fold at the front of the Girl's jacket (sample 25) confirm the results of Groen et al. [4]. The thin $(5 \mu \mathrm{m})$ underlayer (Fig. 11a, indicated by an arrow) contains lead white, yellow ochre, a brown earth pigment and charcoal black. The yellow paint on top contains lead white, yellow ochre, and some ultramarine (Fig. 11a). The upper layer is approximately $30 \mu \mathrm{m}$ thick and would likely have been opaque enough to cover the underlayer; however, the lead white in the upper paint layer has undergone saponification, so it has presumably become more translucent over time. This is presumed from the
SEM-EDX backscatter image (Fig. 11b), which shows that the lead white particles at the surface are amorphous, in contrast to the distinct white particles in the rest of the layer [22].

In comparison, the samples from the shadow part of the Girl's jacket have a thicker underlayer: $\pm 10-12 \mu \mathrm{m}$. Light microscopy of sample 14 showed that the underlayer is dark, and contains a brown earth pigment, red lake and black pigments (Fig. 3a). Some of the black pigment particles could be recognised as charcoal black based on its typical morphology. In UV, the red particles exhibit a pink luminescence, suggesting an organic 


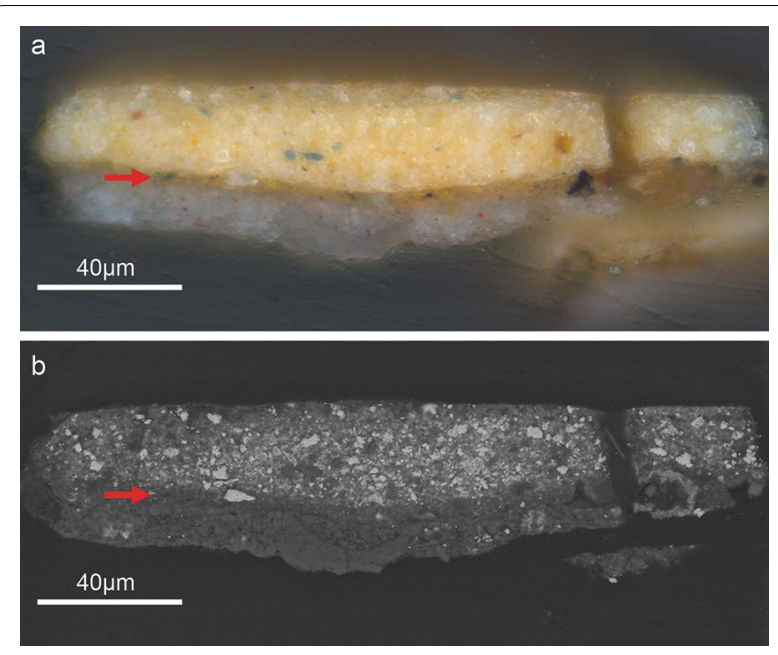

Fig. 11 Sample 25 from the light part of the Girl's jacket, mounted as a cross-section. Sample location indicated with a blue arrow on Fig. 6. a Light microscopy, bright field, b SEM-EDX backscatter, low vacuum. The underlayer is indicated with a red arrow

lake. In UV, thin lines (on the order of $1 \mu \mathrm{m}$ ) exhibit a yellowish luminescence at the interfaces between the ground and underlayer, and the underlayer and paint layer (Fig. 3b). These unpigmented interlayers might be the result of binding medium separating from the paint, or perhaps a thin layer that Vermeer deliberately applied to isolate the underlayer from the layers above and below it. An attempt was made to characterise these interlayers using secondary ion mass spectrometry (SIMS), but so far, they have been too thin to identify. The distinct separation between layers shows that Vermeer left the underlayers to dry-and may have applied a thin intermediate layer-before he applied the surface paint on top.

SEM-EDX mapping of the dark underlayer in sample 14 identified: calcium $(\mathrm{Ca})$, lead $(\mathrm{Pb})$, iron $(\mathrm{Fe})$, sulphur $(\mathrm{S})$, phosphorus $(\mathrm{P})$, aluminium $(\mathrm{Al})$, and small quantities of sodium (Na) and potassium (K). The black pigment was mostly bone black, but a small number of charcoal particles (recognised by their splinter-like morphology) were also identified in the backscatter image. FIB-STEM was performed to characterise the black particles and other pigments in the underlayer at a higher resolution and magnification. In lamella L09 (Fig. 3i), the underlayer was found to contain a fine aluminium phase: possibly an aluminium oxide substrate from the lake pigment. Most of the particles that appear black in visible light are rich in both calcium and phosphorus and were therefore identified as bone black. The combination of light microscopy, SEM-EDX and FIB-STEM shows that Vermeer used two types of black pigment in the dark underlayer of the Girl's clothing: both charcoal and bone black. Surprisingly, some particles in the underlayer (labelled in blue in Fig. 3i) were found to contain both sulphur and calcium together in proportions that suggest gypsum. Both gypsum and chalk are present in the sample of the underlayer, in roughly equal amounts.

The microscopic and elemental analyses of cross-sections from the light and dark areas of her jacket revealed that Vermeer adjusted the colour and thickness of both the underlayers and the upper layers depending on whether the area was meant to depict light or shadow [4]. The final paint layer in the dark areas of the clothing is slightly thinner and more translucent as compared to the lit side. The relative translucency of the pigments used in the upper layer of the dark areas-yellow ochre, ultramarine and red lake-allowed the underlayer to remain slightly visible, and provide more of a visual effect than in the light parts. The underlayers remain (partially) visible in areas of thin or semi-translucent paint, giving the shadows a greenish or bluish hue. The cool hue is caused by blue-hued scattering: the so-called turbid medium effect that occurs when a thin (semi-)translucent light layer is painted on top of a dark underlayer [23].

\section{Discussion}

The results of the investigation into the canvas, ground, outlines and underlayers beneath the surface of Girl with a Pearl Earring can be put into the context of Vermeer's oeuvre to reveal his working process. The height/ width proportions of the original format of Girl with a Pearl Earring (approximately $44.5 \times 39 \mathrm{~cm}$ ) are consistent with most works by Vermeer [24]. Costaras's [24] survey of technical features of Vermeer's paintings shows that the original dimensions of the Girl conform to multiples of the Rhineland inch, suggesting it could have been a standard format. All of Vermeer's canvases that were researched by Costaras [24] were found to have a closed, plain weave. Where the fibres were analysed, they were determined to be flax, indicating linen threads. No fibre analysis has been done on Girl with a Pearl Earring.

Recent computer-assisted thread-level canvas analysis of X-radiographs showed that the thread count of the canvas (horizontal: $14.8 \pm 2.7$ threads $/ \mathrm{cm}$, vertical: $14.6 \pm 3.0$ threads $/ \mathrm{cm}$ ) is similar to those used in many of his other paintings. Vermeer typically used a plainweave canvas with a thread count of between $14 \times 14$ and $15 \times 15$ threads $/ \mathrm{cm}$, as established using hand-counting by Costaras [24]. When compared to the 33 canvas paintings from Vermeer's oeuvre examined using digital thread-counting for the Counting Vermeer project, Girl with a Pearl Earring had seven close count matches (within $1 \mathrm{thread} / \mathrm{cm}$ of each other); however, there were no apparent weave matches to provide evidence that these canvases were manufactured from the same bolt of cloth $[2,25]$. 
There is variation in the tone of the ground layers in his paintings; however, more than half of the grounds contain similar pigments to those detected beneath the Girl with a Pearl Earring [26]. Wald [27] wrote that varying proportions of lead white, chalk, ochre, umber and charcoal black pigments would "produce an underlayer of fairly neutral temperature-which depending on the pigment ratio could vary between a slightly warm brownish to a somewhat cooler grey." Vermeer could have purchased his linen canvas pre-stretched and primed with a ground layer. By the mid-seventeenth century, pre-primed canvases were available in the Netherlands, so he might have purchased one that had been prepared by a primer or 'witter' [24]. Wald [27] stated that the grounds of Vermeer's paintings varied in structure and tone in his early works, but after 1657 , they became more consistent. This could imply that Vermeer was able to acquire pre-primed canvases with more regularity later in his career. The warm light grey tone of the ground of Girl with a Pearl Earring would have provided a neutral base tone, upon which he started to build up the composition. In the Vermeer Studies (1998) publication, researchers described its appearance as "brownish-white" and "a rather dense, yellowish-white" $[4,24]$. Although the original tone of the ground could have been slightly affected by the wax-resin lining that the painting underwent in 1960, the varying opinions suggest that its exact colour is open to interpretation.

Microscopic analyses of the ground of Girl with a Pearl Earring showed that it consists of chalk and lead white (made according to the Dutch stack process), with some earth pigments (including umber) and possibly a fine black pigment. Additional findings about the type of lead white and binding medium were made using analytical techniques that are not reported in this paper. Lead isotope analysis found that the lead ore in the ground was consistent with other Northern paintings, and came from a British source [6]. Micro X-ray powder diffraction ( $\mu$ XRPD) of cross-sections established that the average hydro cerussite to cerussite ratio is estimated as $0.88 \pm 0.04$, which is typical for Dutch stack process lead white [5]. Fourier transform infrared-attenuated total reflectance spectroscopy (FTIRATR) analysis confirmed the presence of chalk, lead white and a drying oil in the ground $[6,7]$. A fragment was analysed using thermally assisted hydrolysis and methylation, pyrolysis gas chromatography-mass spectrometry (THM-Py-GC/MS), which determined that the binding medium of the ground is linseed oil. This confirms the results from the analysis by Groen et al. [4], but specified that the linseed oil had been prepared by heating [8].

The finely-painted black outlines-visible under the microscope (Fig. 10c) and detected with MS-IRR
(Fig. 8b) - have so far only been found around the perimeter of the figure and in a few folds; it is unclear whether Vermeer applied them in other areas of the painting. They may have had a similar function to an underdrawing, which Vermeer loosely followed when applying the paint layers; however, his precise working process remains unclear. He might have begun laying in his composition by drawing the figure with fine outlines, after which he applied the brownish underlayer. An alternate scenario is that he used the lines to re-establish some contours on top of the underlayer (Fig. 10b).

Vermeer applied underlayers with different colours and thicknesses in various parts of Girl with a Pearl Earring: black on one side of her headscarf [7], black beneath the background [8], and light pinkish-yellow beneath her skin [6]. As these distinct areas do not usually overlap, it is difficult to establish the precise order in which they were applied. Using brown-black paint that varied in tone-containing two types of black and other pigments-he established the basic shape of the Girl's jacket, and the distribution of light and shade in an underlayer at an early phase. MS-IRR showed that he applied the brown-black paint of the underlayer vigorously with wide brushstrokes that vary in direction. The underlayer-also visible under high magnification in the cracks (Fig. 9) and in the 'gap' along the contour of the figure (Fig. 10b) - has a similar function to underlayers beneath other paintings by Vermeer. Technical examinations of other paintings from his oeuvre have shown that at an early stage in the painting process, Vermeer established areas of light and shadow $[18,28]$. This preliminary step could be described as 'dead colouring'; however, this term has historically been interpreted in different ways [29]. Gifford [28] distinguishes between two different types of preparatory phases: the term 'monochrome painted sketch' is used to describe the preparatory phase built up in different tones of brown, whereas in other paintings Gifford observed a 'coloured underpainting' beneath specific colour areas. On top of the underlayer(s), Vermeer built up his composition efficiently in the upper layer(s) of paint, sometimes leaving the painted sketch (partially) visible.

The researchers who examined Girl with a Pearl Earring in 1994 described contours where the shadow on the Girl's back meets the background as follows: "the edge of the figure seems blurred; it is not altogether clear where the figure stops and the background starts" [4]. Samples taken from the contour along the back of her neck and back of her headscarf show that Vermeer incorporated more oil and only a small amount of (translucent) pigments in the upper layer of paint as it approached the edge of the forms [4]. This created a gradual transition from the figure to the dark background. Several of his other works seem to have achieved the same effect 
using similar technical means. In Art of Painting (1666, Kunsthistorisches Museum, Vienna), a toned preparation creates a "diffused border between adjacent colour elements. The resulting effect is used by the artist, within darker passages, to simulate the passage of light circulating around objects in space" [27].

The attention that Vermeer paid to the contours of forms is a characteristic feature of his paintings. In other paintings from his oeuvre-including Study of a Young Woman (ca. 1665-1667, Metropolitan Museum of Art, New York) and A Young Woman Seated at a Virginal (ca. 1670-1672, National Gallery, London)-Gifford [28] and Wadum [18] observed two different methods for creating a contour: either by overlapping the paint layers from the different forms, or by leaving a gap between them. Microscopic and infrared techniques now suggest that Vermeer also modified the contours of Girl with a Pearl Earring by leaving the brown-black underlayers partly exposed around the edges of the figure.

\section{Conclusions}

The complementary imaging methods of MS-IRR and 3D digital microscopy helped to answer some of the research questions set out by the Girl in the Spotlight project: (1) What steps did Vermeer take to create the painting? (2) What can we find out about layers beneath the surface? (3) Which techniques did Vermeer use to create subtle optical effects? Vermeer's preparatory steps include both fine black outlines, and broadly-applied underlayers (most containing carbon black) that varied in tone. When compared to the visible light images, the MS-IRR images provide new insight into Vermeer's working methods as well as adjustments he made in the final painting stages. Re-examination of cross-sections showed that Vermeer left the underlayers to dry before he applied the surface paint on top, as is demonstrated by the distinct layers in the cross-sections, sometimes separated by a fluorescent interface. For areas of her jacket in the shadow, he applied the upper layer of paint more thinly than on the lit side, and used more translucent pigments to allow the underlayer to remain slightly visible from beneath.

To complement the macroscale imaging techniques, the precise composition and stratigraphy of these layers at and beneath the surface was determined by the analyses of microscopic samples using SEM-EDX and FIB-STEM. Furthermore, computer-assisted thread-level canvas analysis-using data from the X-radiographsrevealed how the support was prepared. This combination of imaging and macro- and microscale examination techniques has revealed the first steps that Vermeer took to create the Girl with a Pearl Earring.

\section{Abbreviations}

FIB-STEM: focused ion beam-scanning transmission electron microscopy; FTIR-ATR: Fourier transform infrared-attenuated total reflectance spectroscopy; IR: infrared; MS-IRR: multispectral infrared reflectography; SEM-EDX: scanning electron microscopy-energy dispersive X-ray analysis; SIMS: secondary ion mass spectrometry; THM-Py-GC/MS: thermally assisted hydrolysis and methylation, pyrolysis gas chromatography-mass spectrometry; UV: ultraviolet.

\section{Acknowledgements}

The research project The Girl in the Spotlight is a Mauritshuis initiative, led by paintings conservator Abbie Vandivere, with a team of internationally recognised specialists working within the collaborative framework of the Netherlands Institute for Conservation + Art + Science + (NICAS).

The following NICAS partners are actively involved in the research: Rijksmuseum, Delft University of Technology (TU Delft), University of Amsterdam (UvA) and the Cultural Heritage Agency of the Netherlands (RCE). Cooperating in this project are: Shell Technology Centre Amsterdam (STCA), Maastricht University, University of Antwerp, National Gallery of Art Washington DC and Hirox Europe. These institutions have made their equipment, expertise and research time available for the benefit of this project.

NICAS is an interdisciplinary research centre initiated by the division for Physical Sciences of the Netherlands Organisation for Scientific Research (NWO-CEW), within which art history, conservation and restoration, and sciences are united.

This project was made possible with support from the Johan Maurits Compagnie Foundation.

\section{Non-invasive imaging}

X-radiographs, infrared reflectography $(900-1100 \mathrm{~nm})$ and other technical photographs were made by René Gerritsen Art \& Research Photography. Digital 3D microscopy was done by Emilien Leonhardt and Vincent Sabatier from Hirox Europe, Jyfel.

Melanie Gifford and Lisha Glinsman from the National Gallery of Art Washington DC shared their observations about the infrared images, and knowledge about seventeenth-century painting techniques.

Micro-sample analysis

Analysis at Shell Technology Centre Amsterdam (STCA) was coordinated by Bob van Wingerden.

Anne Bruinen, Ron Heeren and Hans Duimel at the Maastricht MultiModal Molecular Imaging Institute (M4I) at Maastricht University examined Sample 10 with SIMS.

Editing

Laurens van Giersbergen assisted with editing and formatting.

\section{Authors' contributions}

AV wrote the main body of the text and was the Head Researcher for the Girl in the Spotlight project. AvL, JD and KD made significant contributions to the content, reviewed the whole text and made valuable comments and suggestions. JD and KD collected the high-resolution multispectral infrared reflectography (MS-IRR) images, mosaicked them, registered them with the colour image, and managed the data. RH carried out the SEM-EDX mapping and FIB-STEM analyses at Shell Technology Centre Amsterdam (SCTA), and reviewed and contributed to the relevant parts of this publication. AvL performed light microscopy and SEM-EDX analysis at the Ateliergebouw, Amsterdam. RE did the data management for the project, performed the computerassisted thread-level canvas analysis, lens-corrected and stitched the 3D digital microscope photographs, stitched and registered the technical photographs, and reviewed the text. EL did the examination with the 3D digital microscope, provided the relevant images, and wrote the section with the experimental method. All authors read and approved the final manuscript.

\section{Funding}

The Netherlands Institute for Conservation + Art + Science + funded the participation of the NICAS partners in the project, including use of analytical equipment and the time devoted to the project by scientists from the RCE, TU Delft, University of Amsterdam and the Rijksmuseum.

The Girl in the Spotlight project was made possible with support from the Johan Maurits Compagnie Foundation. 


\section{Availability of data and materials}

The datasets used and/or analysed during the current study are available from the corresponding author on reasonable request.

\section{Competing interests}

The authors declare that they have no competing interests.

\section{Author details}

${ }^{1}$ Conservation Department, Mauritshuis, Plein 29, 2511 CS The Hague, The Netherlands. ${ }^{2}$ Rijksmuseum Conservation \& Science, Ateliergebouw, Hobbemastraat 22, 1017 ZC Amsterdam, The Netherlands. ${ }^{3}$ Scientific Research Department, National Gallery of Art, 6th and Constitution Avenue NW, Washington, D.C. 20565, USA. ${ }^{4}$ Shell Global Solutions International B.V., Grasweg 31, 1031 HW Amsterdam, The Netherlands. ${ }^{5}$ Conservation \& Restoration, University of Amsterdam, Johannes Vermeerplein 1, 1071DV Amsterdam, The Netherlands. ${ }^{6}$ Hirox Europe-Jyfel Corporation, 300 Route Nationale 6, Le bois des côtes, 69760 Limonest, France.

Received: 18 May 2019 Accepted: 13 August 2019

Published online: 02 September 2019

\section{References}

1. Vandivere A, Wadum J, van den Berg KJ, van Loon A. From 'Vermeer Illuminated' to 'The Girl in the Spotlight': approaches and methodologies for the scientific (re-)examination of Vermeer's Girl with a Pearl Earring. Heritage Science. 2019;. https://doi.org/10.1186/s40494-019-0307-5.

2. Johnson CR Jr., Sethares WA. Counting Vermeer. The Hague: RKD, 2017. http://countingvermeer.rkdmonographs.nl/appendix-i-paintings-repor ts-and-x-radiographs/l22-girl-with-a-pearl-earring. Accessed 24 Feb 2019.

3. Delaney JK, Thoury M, Zeibel JG, Ricciardi P, Morales KM, Dooley KA. Visible and Infrared imaging spectroscopy of paintings and improved reflectography. Herit Sci. 2016;4:6. https://doi.org/10.1186/s40494-016-0075-4.

4. Groen K, van der Werf I, van den Berg K, Boon J. Scientific examination of Vermeer's "Girl with a Pearl Earring". In: Gaskell I, Jonker M, editors. Vermeer studies: studies in the history of Art 55. New Haven and London, Washington DC: National Gallery of art, Yale University Press; 1998. p. 168-83.

5. De Meyer S, Vanmeert F, Vertongen R, van Loon A, Gonzalez V, Dik J, Van der Snickt G, Vandivere A, Jannsens K. Imaging secondary reaction products at the surface of Vermeer's Girl with the Pearl Earring by means of in situ macro X-ray powder diffraction scanning. Herit Sci. 2019;(submitted).

6. Van Loon A, Vandivere A, De Meyer S, Vanmeert F, Janssens K, Gonzalez V, Delaney J, Dooley K, D'Imporzano P, Davies GR, Leonhardt E, Haswell $R$, de Groot S, Proaño Gaibor AN. Beauty is skin deep: the skin tones of Vermeer's Girl with a Pearl Earring. Herit Sci. 2019;(in preparation).

7. Van Loon A, Vandivere A, Gambardella A, Gonzalez V, Keune K, Haswell R, de Groot S, Proaño Gaibor AN, Leonhardt E, Dooley K, Delaney J. Out of the blue: Vermeer's use of ultramarine in Girl with a Pearl Earring. Herit Sci. 2019; (in preparation).

8. Vandivere A, van Loon A, Dik J, Callewaert T, Haswell R, van den Berg KJ. Fading into the background: the dark space surrounding Vermeer's Girl with a Pearl Earring. Herit Sci. 2019;(submitted).

9. Van der Maaten L, Erdmann RG. Automatic thread-level canvas analysis: a machine-learning approach to analyzing the canvas of paintings. IEEE Signal Process Mag. 2017;32(4):38-45. https://doi.org/10.1109/ MSP.2015.2407091.

10. Conover DM, Delaney JK, Loew MH. Automatic registration and mosaicking of technical images of old master paintings. Appl Phys A. 2015;119(4):1567-75. https://doi.org/10.1007/s00339-015-9140-1.

11. Giannuzzi LA, Drown JL, Brown SR, Irwin RB, Stevie FA. Focused ion beam milling and micromanipulation lift-out for site specific cross-section TEM specimen preparation. Mater Res Symp Proc. 1997;480:19-27. https://doi. org/10.1557/PROC-480-19.

12. Van de Wetering E. Rembrandt: the painter at work. Amsterdam: Amsterdam University Press; 1997. p. 111-23.

13. Johnson R, Johnson D, Verslype I, Lugtigheid R, Erdmann R. Detecting weft snakes. Art Matters. 2013;5:48-52.
14. Wadum J, with contributions by Hoppenbrouwers $R$ and Struick van der Loeff L. Vermeer Illuminated. Conservation, Restoration and Research. Wormer: V+K Publishing/Inmerc; The Hague: Mauritshuis; 1994.

15. De Mayerne TT. Pictoria, sculptoria et quae subalternarum artium (the 'Mayerne manuscript'). Sloane MS 2052. London: British Museum, 1620-1646. f. 5r. http://www.bl.uk/manuscripts/Viewer.aspx?ref=sloan e_ms_2052_f005r. Accessed 24 Feb 2019.

16. Kühn H. A study of the pigments and the grounds used by Jan Vermeer. Technical Reports: report and studies in the history of art, vol. 2, 1968; 2:176-202. JSTOR. www.jstor.org/stable/42618100.

17. Gettens RJ, Kühn H, Chase WT. Lead White. In: Roy A, editor. Artists' Pigments: a handbook of their history and characteristics: 2. National Gallery of Art, Washington CD; Archetype Publications, London; 1993; p. 67-81. https:// www.nga.gov/research/publications/pdf-library/artists-pigments-vol2.html.

18. Wadum J. Contours of Vermeer. In: Gaskell I, Jonker M, editors. Vermeer studies: studies in the history of art 55. New Haven and London, Washington DC: National Gallery of Art, Yale University Press; 1998. p. 201-23.

19. Van Asperen De Boer JRJ. Reflectography of paintings using an infrared vidicon television system. Stud Conserv. 1969;14(3):96-118. https://doi. org/10.2307/1505392.

20. Delaney JK, Trumpy G, Didier M, Ricciardi P, Dooley KA. A high sensitivity, low noise and high spatial resolution multi-band infrared reflectography camera for the study of paintings and works on paper. Herit Sci. 2017;1(5):32. https://doi.org/10.1186/s40494-017-0146-1.

21. Wadum J, Costaras N. Johannes Vermeer's 'Girl with a Pearl Earring' De- \& Re-Restored.'In: Restauration, Dé-Restauration, Re-Restauration..., Preprints of ARAAFU's 4th international symposium, Paris 5-7 October 1995, p. 163-172.

22. Keune K, van Loon A, Boon J. SEM backscattered-electron images of paint cross sections as information source for the presence of the lead white pigment and lead-related degradation and migration phenomena in oil paintings. Microsc Microanal. 2011;5(17):696-701. https://doi. org/10.1017/S1431927610094444.

23. Behault S. Blue-hued scattering in Flemish Baroque and Dutch Golden Age paintings. In: Simone G, Hardeberg JY, Farup I, Davis A, Parraman C, editors. Color-Coded: The CREATE 2010 Conference. Gjøvik: Norway; 2010. p. 86-90.

24. Costaras N. A study of the materials and techniques of Johannes Vermeer. In: Gaskell I, Jonker M, editors. Vermeer studies: studies in the history of art 55. New Haven and London: National Gallery of Art, Yale University Press, Washington DC; 1998. p. 145-67.

25. Johnson R. Counting Vermeer: exploiting weave maps: 6.1 weave matches. The Hague: RKD; 2017. http://countingvermeer.rkdmonographs. nl/chapter-6-exploiting-weave-maps/weave-matches. Accessed 24 Oct 2017.

26. Noble P, Verslype I. Counting Vermeer: using weave maps to study Vermeer's canvases: 2.5.2 Grounds. The Hague: RKD; 2017. http://countingve rmeer.rkdmonographs.nl/chapter-2-the-use-of-x-radiographs-in-thestudy-of-paintings/2.4.2-x-rays-and-vermeer2019s-painting-technique/ grounds. Accessed 21 Oct 2017.

27. Wald R. The art of painting: Observations on approach and technique. In: Haag S, Oberthaler E, Pénot S, editors. Vermeer, Die Malkunst - Spurensicherung an einem Meisterwerk. Exhibition catalogue from Kunsthistorischen Museums Wien. Vienna; 2010. English translation of essay p. 312-327.

28. Gifford EM. Painting light: recent observations on Vermeer's technique. In: Gaskell I, Jonker M, editors. Vermeer studies: studies in the history of art 55. New Haven and London, Washington DC: National Gallery of Art, Yale University Press; 1998. p. 185-200.

29. Van Hout N. Functies van Doodverf: de onderschildering en andere onderliggende stadia in het werk van P.P. Rubens. PhD dissertation. Leuven: KU Leuven, 2005. https://limo.libis.be/primo-explore/fulldispla $y$ ?docid=LIRIAS1799124\&context=L\&vid=Lirias\&search_scope=Liria s\&tab=default_tab\&lang=en_US\&fromSitemap $=1$. Accessed 24 Feb 2019 .

\section{Publisher's Note}

Springer Nature remains neutral with regard to jurisdictional claims in published maps and institutional affiliations. 